\title{
XVIII. Remarks on the existence and mechanism of the negative or protecting rays of the sun
}

\section{John William Draper M.D.}

To cite this article: John William Draper M.D. (1847) XVIII. Remarks on the existence and mechanism of the negative or protecting rays of the sun, Philosophical Magazine Series 3, 30:199, 87-93, DOI: 10.1080/14786444708645657

To link to this article: http://dx.doi.org/10.1080/14786444708645657

Published online: 30 Apr 2009.

Submit your article to this journal $₫$

Џ Article views: 2

Q View related articles $\square$ 
In the above table it will be observed that the hard steel bar was slightly increased in length every time that contact with the battery was broken, although a considerable diminution of the magnetism of the bar took place at the same time. I am disposed to attribute this effect to the state of tension in the hardened steel, for I find that soft iron wire presents a similar anomaly when stretched tightly.

On inspecting the tables, it will be remarked that the elongation is, for the same intensity of magnetism, greater in proportion to the softness of the metal. It is greatest of all in the well-annealed iron bars, and least in the hardened steel. This circumstance appears to me to favour the hypothesis that the phænomena are produced by the attractions taking place between the magnetic particles of the bar, an hypothesis in perfect accordance with the law of elongation which I have pointed out.

[To be continued.]

XVIII. Remarks on the Existence and Mechanism of the Negative or Protecting Rays of the Sun. By JoHn WILliam Draper, M.D., Professor of Chemistry in the University of New York*.

I $\mathrm{N}$ a letter published in the Philosophical Magazine, Nov. 1842 , I had occasion to make some incidental remarks respecting a class of rays existing in the sun-light, which have the quality of exerting a negative or antagonizing action upon those engaged in producing Daguerreotype results.

In October last, MM. Foucault and Fizeau having made a communication to the French Academy of Sciences to a similar effect, and M. Edmond Becquerel, in criticising their results, having referred to me as the original author of the fact, I may on this occasion be excused for offering a few observations on this, which perhaps is destined to become one of the most important phænomena in relation to the chemical action of the sun-light.

That the opposite ends of the solar spectrum possess opposite qualities is an idea which, far from originating with me, has been floating anong chemists for many years. The first distinct statement with which $I$ am acquainted in relation to it occurs in a work published by $\mathrm{Mr}$. B. Wilson, the second edition of which dates as early as 1776. It is entitled "A $\mathrm{A}$ Series of Experiments on Phosphori." He shows that it is the more refrangible rays which excite the phosphorescence of sulphuret of lime, but the less refrangible ones extinguish it rohen shining.

* Communicated by the Author. 
In 1801 Ritter found that chloride of silver which had been blackened in the violet rays, had its colour partially restored when placed in the red. He states also that phosphorus, which is oxidized with the production of fumes in the invisible red, is instantly extinguished in the violet.

The well-known experiments of Wollaston with guaiacum served to show the opposite relations of the red and violet rays. It is remarkable, that he subsequently abandoned this interpretation of the phænomenon, on discovering that green guaiacum changed its colour by the application of a hot silver spoon.

In 1839 Sir J. Herschel encountered the same action in the case of some of the preparations of silver. His first idea was that of a positive and negative polarity of the spectrum; but this was subsequently modified for the reasons set forth in his memoir*.

From the time when I examined the Daguerreotype spectrum in Virginia in 1842, I have never doubted the actual existence of these negative or protecting rays; and on this occasion, when that existence is re-asserted by Lerebours, Fizeau and Foucault, I will make known certain new facts, premising that I do not think the views taken by $M$. Becquerel are correct. They are founded on what seems to me to be a misapprehension of the phænomenon of the Daguerreotype.

A. Daguerreotype plate can exhibit three different varieties of surface:-1st, a black aspect on those regions where it has been unaffected by light; 2nd, various shades of white ; 3rd, a coloured blackness, the tint of which may be of a deep watch-spring, or sometimes of an olive shade. Persons familiar with the process will understand completely what I mean. The first of these conditions is represented in the deep shadows of such a photograph, the places where the light never acted; the second is exhibited in the various intensities of whiteness, which constitute the figures of the picture, the whiteness varying in intensity according to the intensity of the light; the third is the solarized or overdone condition, which arises from too long an exposure to the rays. Like the first this may be spoken of as a blackness, but in reality it is a dark green, or blue, or tawny tint. It is this solarized condition of surface which $M$. Becquerel confounds with the first, the blackness arising from the unchanged state; and it is precisely on this point that the whole argument turns. For the sake of having distinctive words to mark out these three conditions, I will call the first the unaffected state, the second the white state, and the third the solarized state.

- Phil, Trans. 1840, $\$ 60, \& c$. 
The observations I made in Virginia were as follows. That if a solar spectrum was received on a Daguerreotype plate on which a weak daylight was simultaneously acting, the red, orange, yellow, green, and part of the blue rays, arrested the action of the daylight on that portion of the plate on which they fell, and maintained it in the unaffected state; whilst the residue of the blue, the indigo and violet, carried their part of the plate to a completely solarized condition. This therefore seemed to justify the assertion, that the less refrangible rays protect Daguerre's preparation from the action of a diffused daylight.

It was also found that if the plate was exposed to the daylight for a few seconds, so that had it been then mercurialized it would have whitened uniformly all over, on being made to receive the spectrum the less refrangible rays actually carried it back to the unaffected condition, reversing what had been already done. Whilst the more refrangible rays were forcing it on to the solarized state, these were returning it into the condition of shadow : they therefore not only protect, but seem even to exert a negative or antagonistic action.

The following observation appears to me to be in contrast with the beautiful explanation which Sir J. Herschel gives of the phænomena of one of these specimens, and moreover to have a very significant meaning. I found that it was perfectly immaterial whether the exposure to the spectrum was for thirty seconds or one hour-the result was the same. 'The final action had been produced, the less refrangible rays had carried their region to the unaffected state, while the more refrangible had solarized theirs. Now if the phænomenon was due, as M. Becquerel supposes, to an unequal action of the same kind in the different rays, it is obvious that the final result ought to depend on the time of exposure; the red ray, aided by the daylight, should carry its portion through the various shades of white, and solarize it at last. But this in the longest exposure never takes place; that part of the plate remains as though a ray of light had never fallen upon it.

Such are the facts I observed, and they seem to have been reproduced by MM. Foucault and Fizeau ; but there are also others of a much more singular nature. In these Virginia specimens the same protecting action reappears beyond the violet.

The only inpressions in which I have ever seen this protecting action beyond the violet, are those made in Virginia in 1842 ; they were made in the month of July. Struck with this peculiarity, on ny return to New York the following August I made many attempts to obtain similar specimens, but in no inPhil. Mag. S. 3. Vol. 30. No. 199. Feb. 1847. 
stance could the extra-violet protecting action be traced, though the analogous action of the red, orange, yellow, green and blue, was perfectly given. Supposing, therefore, that the difference must be due either to impurities in the iodine or to differences in the method of conducting the experiment, $I$ tried it again and again in every possible way. To my surprise I soon found that the negative effect was gradually disappearing; and on Sept. 29 it could no longer be traced, except at the highest part corresponding to the yellow and green rays. In December it had become still more imperfect, but on the 19th of the following March the red and orange rays had recovered their original protective power. It seemed, therefore, that in the early part of the year a protective action had made its appearance in the red ray, and about July extended over all the less refrangible regions, and as the year went on it had retreated upwards.

Are there then periodic changes in the nature of the sun's light? The absorptive action of the earth's atmosphere is out of the question: if that were the cause, the character of these spectrum impressions should vary with the hour of the day. Or is it not more probable that these singular phænomena rather depend on incidental changes in the experiment, such as external temperature, variations of moisture, the colour of the sky, \&c.?

Under proper circumstances there is no difficulty in exhibiting the power which the less refrangible rays exert in arresting the action of the daylight: under such circumstances a Daguerreotype impression of the sun's spectrum yields all three of the varieties of surface before alluded to. The plate in the less refrangible and extreme violet region is unaffected; a narrow space of white separates these unaffected portions from the indigo and violet spaces, which are in a highly solarized state.

But a totally different result is obtained when the daylight is not allowed to fall on the plate, either before or during its exposure to the spectrum. Under these circumstances the rays which would otherwise protect now act on the plate and slowly whiten it. A Daguerreotype spectrum formed in darkness and without previous exposure to the light, exhibits a white stain over all the less refrangible regions, and bears a marked contrast to one formed under the simultaneous action of a weak daylight. For brevity I will call the former the spectrum of darkness, and the latter the spectrum of daylight. The following are some additional observations.

In the spectrum of darkness there is in the white stain a 
point of maximum action. This corresponds with the maximum of protection in the spectrum of daylight.

The white stain of the spectrum of darkness is apparently narrower than the protected space in the spectrum of daylight.

Rays of luminous or of non-luminous heat projected on the darkness or daylight spectra during their formation appear to exert no kind of special influence on the result.

The white fringe which borders the solarized portion is not due to anything analogous to conduction. These chemical changes, unlike thermal changes, cannot be conducted.

By interposing between the prism and the Daguerreotype plate a convex lens of short focus, so as to intercept in succession each of the coloured rays, I threw all over the plate, while the spectrum was in the act of being impressed upon it, red, orange, yellow, \&c. lights in succession; the object being to ascertain how far the impressed spectrum would change when these monochromatic rays were used along with dayligbt, Sir J. Herschel having previously showed in similar experiments that new phænomena arise during the conjoint action of rays*. The following are some of the observations I made; their date is Sept. 24, 184.2.

The red ray when projected increases the length of the solarized portion, and also of its white extremities.

The yellow ray shortens the solarized portion.

The green ray exerts a greater action of the same kind.

The indigo ray gives a most remarkable result. It totally inverts the action of the less refrangible rays; and they solarize the plate, acting precisely in the same way that the more refrangible rays commonly do, causing it to exhibit a watchspring lustre.

I further found that when different rays are brought to act upon each other, the result does not alone depend upon their intrinsic differences, but also on their relative intensities. Thus the green and lower half of the blue rays, when of a certain intensity, protect the plate from the action of the daylight; but if of a less intensity, they aid the daylight.

The red and orange rays, when of a certain intensity, increase the action of daylight on the plate; but if of a less intensity, they restrain it.

These facts seem to be connected with the circumstance that there is often to be traced on Daguerreotype plates a remarkable difference between the central and lateral parts of a spectrum. Thus if a line be drawn through the centre of such a spectrum and a parallel to it on one of the edges, the action at any point on the central line is the reverse of that at

* Phil. Trans. 1840, $§ 64$.

$\mathrm{H} 2$ 
the corresponding point on the edge. A similar remark, as respects impressions on paper, has been previously made by Sir J. Herschel.

Such are the chief facts I have observed in relation to the Daguerreotype spectrum. It would seem at first sight that their diversity is so great that we can have but little hope of reducing them to a common system of results originating in the same cause. I have however been long led to believe that the explanation is to be met with in the great and fertile principle of interference. From this point of view I regard the action of rays of every kind as being essentially positive, and that action mainly consists in impressing a vibratory movement on the atoms of the decomposing substance. It is to my mind a fact of no common significance, that in those Virginia specimens the places of maximum protection in the less and more refrangible regions fall where the lengths of the luminous waves have the extraordinary relation of $2: 1$. Then, when we also see that, before a perfect neutralization of action between two rays ensues, those rays must be adjusted in intensity to each other, does it not show that interference of some kind is going on? Again, the yellow ray is in numberless instances the ray which most completely antagonizes those at the red and violet extremes of the spectrum: to use the language of Sir J. Herschel, "this ray may be considered as marking a sort of chemical centre, a point of equilibrium, or rather a change of action in the spectrum." I cannot avoid seeing that these phænomena are connected with the remarkable fact, that the waves of red, yellow and violet light, are of lengths which correspond to $2,1 \frac{1}{2}, 1$.

If then a powerful yellow ray can hold in check a feeble violet one, and prevent it from decomposing iodide of silver, merely because their relation of length is in the proportion of $1 \frac{1}{2}$ to 1 , it should follow on the same principles, that a red ray acting conjointly with a violet should give rise to an increased effect, because the lengths have now become $2: 1$. And that this in reality is the case $I$ found by direct experiment; for on projecting the red upon the violet, so that the colours should half overlap each other, I found that at the point of concourse the plate instantly solarized, and assumed a splendid green metallic colour.

I have now explained the acceptation in which I receive the term negative ray as a synonym (in this instance of iodide of silver) for the yellow ray, and alluded to the mechanism which seems to be the cause of protecting action generally. Perhaps on a review of his own experiments M. Becquerel may find reason to believe that there are in reality antagonizing 
actions in different parts of the spectrum; actions not limited to the Daguerreotype, but occurring in all kinds of cases. They have been met with by every one who has examined the spectrum with sensitive papers, and, in a totally different series of phænomena, M. Becquerel has himself furnished a most conclusive illustration. He shows that when sulphuret of lime and other phosphorescent bodies in a shining state are exposed to the spectrum, the more refrangible rays increase the glow, but the less extinguish it at once. What is to be made of a fact like that?

It is proper to observe, that some of the phænomena recorded in this communication which seem to be in opposition to the principle set forth are not so in reality. All reasonings founded on the decomposition of light by the prism, and the action of the prismatic spectrum on changeable surfaces, are liable to error. In a memoir which I shall soon publish " $\mathrm{On}$ the Production of Light by Heat," this point will be particularly dwelt on ; for the present it is sufficient to say, that the only method free from these difficulties is to employ the interference spectrum formed by a ruled surface or a grate; a method which was proposed eight years ago by Sir J. Herschel with a view of getting rid of the disturbing agencies arising from the ideal coloration of glass, and which I first carried into effect in 1844 with so much success, that the resulting Daguerreotype impressions contained Fraunhofer's lines, even with microscopic minuteness. With this spectrum we avoid a far more serious difficulty than that of the ideal coloration of glass, a difficulty arising from the magnitude of the refracting faces of the prism. It is this which makes a prismatic spectrum blacken paper, made sensitive with the bromide of silver, from the red to the violet end; whereas the interference spectrum shows that the true action is confined to the more refrangible side, and stops short of the centre of the yellow space.

University, New York,

Dec. 24, 1846.

XIX. Note to a former paper on the Theory of the Aberration of Light. By the Rev. Professor Poweln.

SINCE the publication of my paper in a late Number of

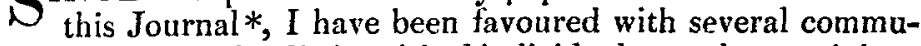
nications from the distinguished individuals on whose opinions I have there commented; and their friendly criticisms seem to call for a brief supplementary remark.

$$
\text { - Phil. Mag., Dec. } 1846 .
$$

